\title{
The impact of COVID-19 first wave national lockdowns on perinatal outcomes: a rapid review and meta-analysis
}

\author{
Christine Vaccaro ${ }^{1}$, Farida Mahmoud ${ }^{2}$, Laila Aboulatta', Basma Aloud ${ }^{1}$ and Sherif Eltonsy ${ }^{1,3^{*}}$
}

\begin{abstract}
Background: Since the emergence of COVID-19, preventative public health measures, including lockdown strategies, were declared in most countries to control viral transmission. Recent studies and anecdotes have reported changes in the prevalence of perinatal outcomes during national COVID-19lockdowns. The objective of this rapid review was to evaluate the impact of COVID-19 lockdowns on the incidence of low birth weight (LBW), preterm birth (PTB), and stillbirth.
\end{abstract}

Methods: Two reviewers searched EMBASE, CORD-19, LitCovid (PubMed), WHO Global research on corona virus disease (COVID-19), and MedRxiv for studies published in English from the first reports on COVID-19 until 17 July 2021. Perinatal outcomes of interest included LBW $(<2500 \mathrm{~g})$, PTB $(<37$ weeks $)$, and stillbirth.

Results: Of the 1967 screened articles, 17 publications met the inclusion criteria (14 cohort studies, 1 case control and 2 cross-sectional studies). Studies included data from Denmark, UK, Ireland, Nepal, Italy, Israel, Botswana, Australia, China, Netherlands, Saudi Arabia, Austria, Zimbabwe, India, and Spain. The total sample size ranged from 3399 to 1,599,547 pregnant women. Thirteen studies examined PTB with conflicting results, reporting both an increase and a decrease in PTB incidence, with odds ratios [95\% Cl] ranging from $0.09[0.01,0.40]$ to $1.93[0.76,4.79]$. Three studies found a decrease in LBW rates during lockdowns, one of which was statistically significant, with a rate ratio of 3.77 $[1.21,11.75]$. Ten studies examined stillbirth rates, including four studies reporting a statistically significant increase in stillbirth rates, with adjusted relative risk ranging from $1.46[1.13,1.89]$ to $3.9[1.83,12.0]$. Fourteen studies contained data that could be combined in a meta-analysis comparing perinatal outcomes before and during lockdown. We found that lockdown measures were associated with a significant risk of stillbirth with $\mathrm{RR}=1.33[95 \% \mathrm{Cl} 1.04,1.69]$ when compared to before lockdown period. However, lockdown measures were not associated with a significant risk of PTB, LBW and VLBW compared to prepandemic periods.

Conclusions: This review provides clues about the severity of the indirect influence of COVID-19 lockdown implementation; however, the criteria that lead to unexpected changes in LBW, PTB, and stillbirth remains unclear. Large studies showed conflicting results, reporting both increases and decreases in selected perinatal outcomes. Pooled results show a significant association between lockdown measures and stillbirth rates, but not low birth weight rates. Further studies examining the differences in other countries'lockdowns and sociodemographic groups from low to middle-income countries are needed. Exploration of perinatal outcomes during COVID-19 lockdown poses an

\footnotetext{
*Correspondence: Sherif.Eltonsy@umanitoba.ca

${ }^{3}$ The Children's Hospital Research Institute of Manitoba, Winnipeg,

Canada

Full list of author information is available at the end of the article
}

(c) The Author(s) 2021. Open Access This article is licensed under a Creative Commons Attribution 4.0 International License, which permits use, sharing, adaptation, distribution and reproduction in any medium or format, as long as you give appropriate credit to the original author(s) and the source, provide a link to the Creative Commons licence, and indicate if changes were made. The images or other third party material in this article are included in the article's Creative Commons licence, unless indicated otherwise in a credit line to the material. If material is not included in the article's Creative Commons licence and your intended use is not permitted by statutory regulation or exceeds the permitted use, you will need to obtain permission directly from the copyright holder. To view a copy of this licence, visit http://creativecommons.org/licenses/by/4.0/. The Creative Commons Public Domain Dedication waiver (http//creativeco mmons.org/publicdomain/zero/1.0/) applies to the data made available in this article, unless otherwise stated in a credit line to the data. 
opportunity to learn from and make changes to promote the reduction of the leading causes of childhood mortality worldwide.

Keywords: Low birth weight, Stillbirth, Preterm birth, COVID-19, Lockdown

\section{Background}

COVID-19 has spread worldwide since the World Health Organization (WHO) declared it as a Public Health Emergency of International Concern on 30 January 2020 [1]. In addition to various public health measures, lockdown strategies - of various degrees - were declared in most countries to control the spread of COVID-19. The implementation of lockdowns and the degree of outbreaks had the potential to affect individuals' health and access to services, like health care, financial benefits, and social support. Although pregnant patients were encouraged not to put their health on hold, as antenatal care is beneficial for maternal and fetal health, there are currently limited clinical reports on the influence of national lockdowns on pregnancy and perinatal outcomes [2].

Globally, the incidence of preterm births (PTB) (10.6\%), infants born with a low birth weight (LBW)(14.6\%), and stillbirths (1.84\%) are declining [3-5]. Although these outcomes' etiology is not clear, they are associated with factors including environmental conditions and are still most prevalent in low to middle income countries [3-5]. Recently, the media have covered several reports and anecdotes of positive influence of COVID-19, in the form of reduced rates of preterm births observed in hospitals. Several Canadian cities have reported a decrease in preterm births, including a 37\% decline in PTB in Calgary, $30 \%$ decline in Ottawa, and 80\% decline in Halifax [6-8]. Further exploration of perinatal outcome changes during the first wave period poses an opportunity to learn from and make policy changes to promote the reduction of the leading causes of childhood mortality worldwide in the next wave and other pandemics. The objective of this rapid review was to evaluate the impact of COVID-19 lockdowns on the incidence of low birth weight (LBW), preterm birth (PTB), and stillbirth in pregnant women.

\section{Methods}

Two reviewers searched EMBASE, CORD-19, LitCovid (PubMed), WHO Global research on corona virus disease (COVID-19) and MedRxivfor clinical studies published in English from 01 January 2020 to 17 July 2021 using a search strategy comprised of the following terms: "perinatal outcomes" OR "stillbirth" OR "low birth weight" OR "preterm" AND "pregnancy" AND "quarantine" OR "lockdown" AND "COVID-19" and MeSH terms "Pregnancy", "Pregnancy Outcome", "Infant", "Low Birth Weight", "Stillbirth", "Birth weight",
"Social Isolation" or "Pandemics", "Quarantine", "Premature Birth" or "Infant", "Premature" and "Coronavirus." 1967 studies were assessed independently by the screeners (Christine Vaccaro and Farida Mahmoud) using a screening tool (Additional file 1), and any disagreements were resolved through discussion. Studies and accepted articles that reported neonatal and perinatal outcomes of COVID-19 in pregnancy, namely birth weight, preterm birth rate and/or stillbirth rate were included. Furthermore, studies that included singleton or multiple pregnancies were included; however, case reports, review articles, and abstracts presented at international conferences were excluded. The following data were collected from each study: study design, year, country, study period, data source, and whether the study population included singleton or multiple pregnancies. Definition of low birth weight and premature birth, defined by authors in each study, and the estimated Odds Ratio (OR) or Risk Ratio (RR) were extracted, as shown in Tables 1 and 2. The percentage of increase/decrease for each perinatal outcome was calculated when data were available. Data were synthesized using Review Manager for Windows (RevMan, version 5.3, Copenhagen: The Nordic Cochrane Centre, The Cochrane Collaboration, 2014). Risk ratio (RR) was used as the outcome measure. We used the DerSimonian-Laird random-effects model to exclude between-study heterogeneity. Statistical heterogeneity was assessed by the $\mathrm{I}^{2}$ statistic and Cochrane's Q-statistic; $p<0.05$ indicating significant heterogeneity.

\section{Results \\ Preterm birth rates}

Since the emergence of COVID-19, eight studies have reported a decrease in national preterm birthrates (Table 1) $[9,12,14,16,18,19,23,24]$.

The most extensive quasi-experimental study to date ( $n=1,599,547$ singleton newborns) reported a $15-23 \%$ decrease in preterm birth rates [9]. Using a regression discontinuity design, Been et al. examined the Netherlands COVID-19 mitigation measures' impact over several periods of the first wave of COVID-19. Although preterm birth rates decreased across all gestational age categories less than 37 weeks, only the 32-36-week stratum was statistically significant [9].

All three notable dates in the Netherlands COVID-19 mitigation strategy (March 9, March 15, and March23) were further stratified into four-time windows $( \pm 1$ to 


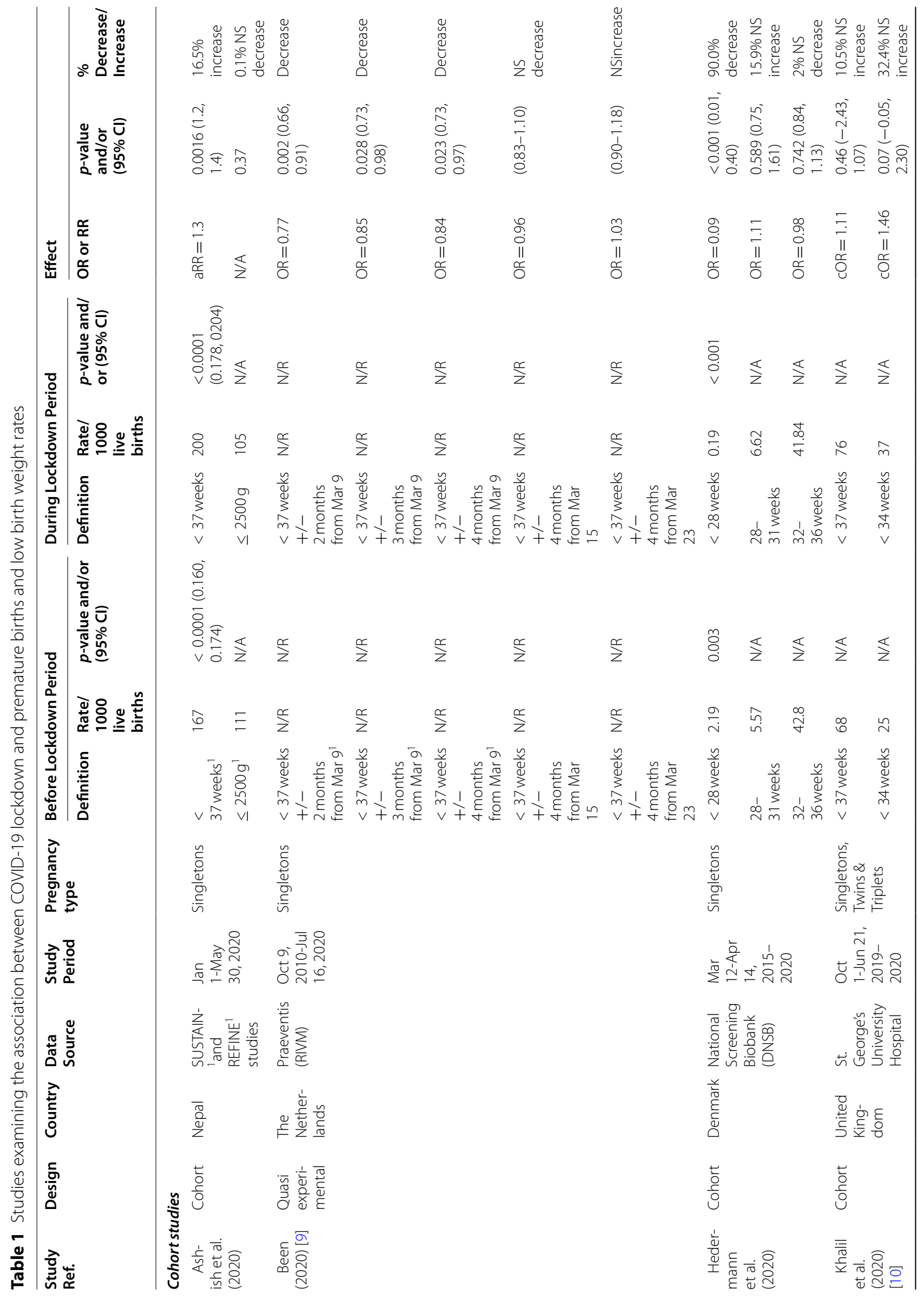




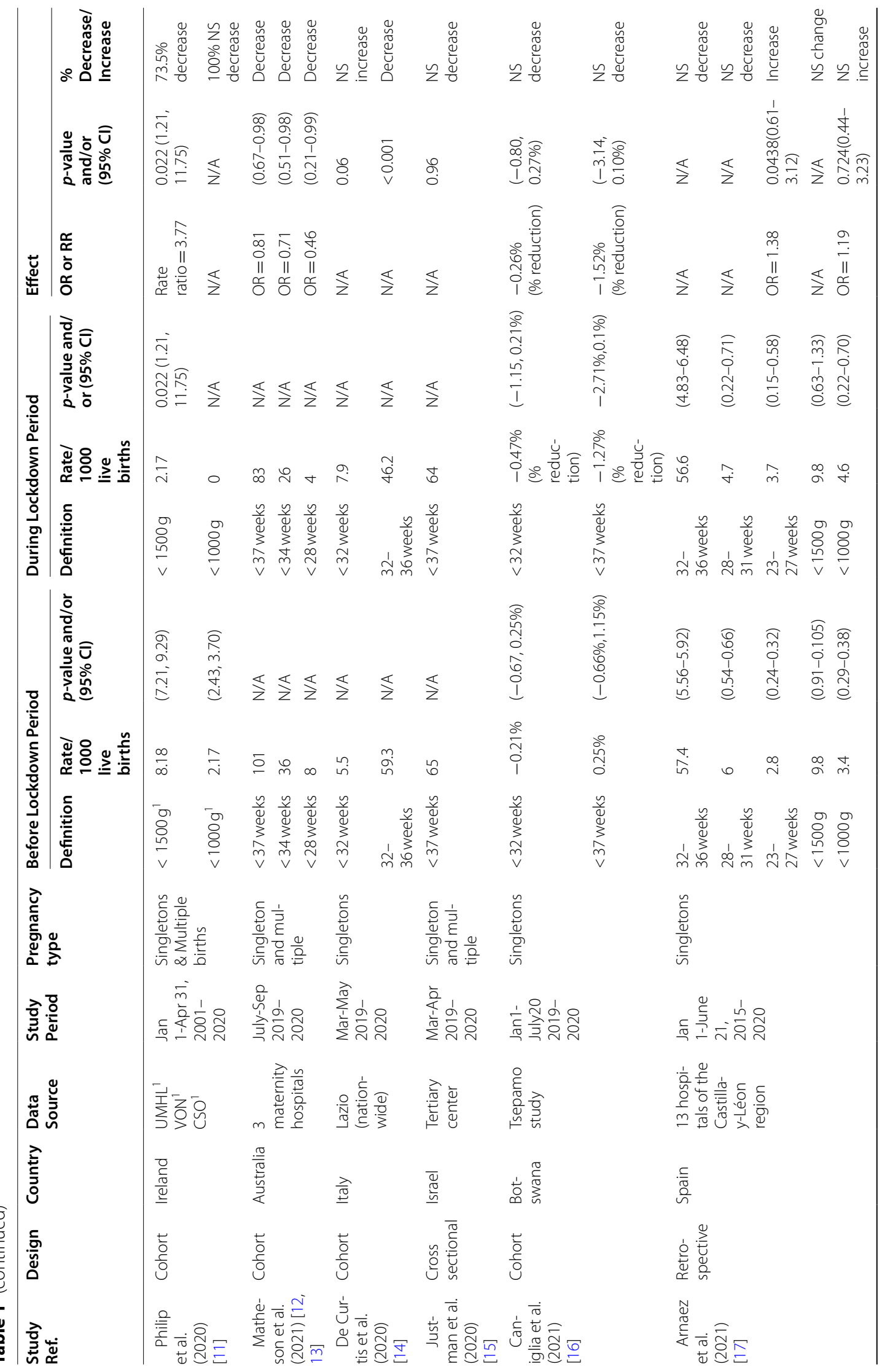




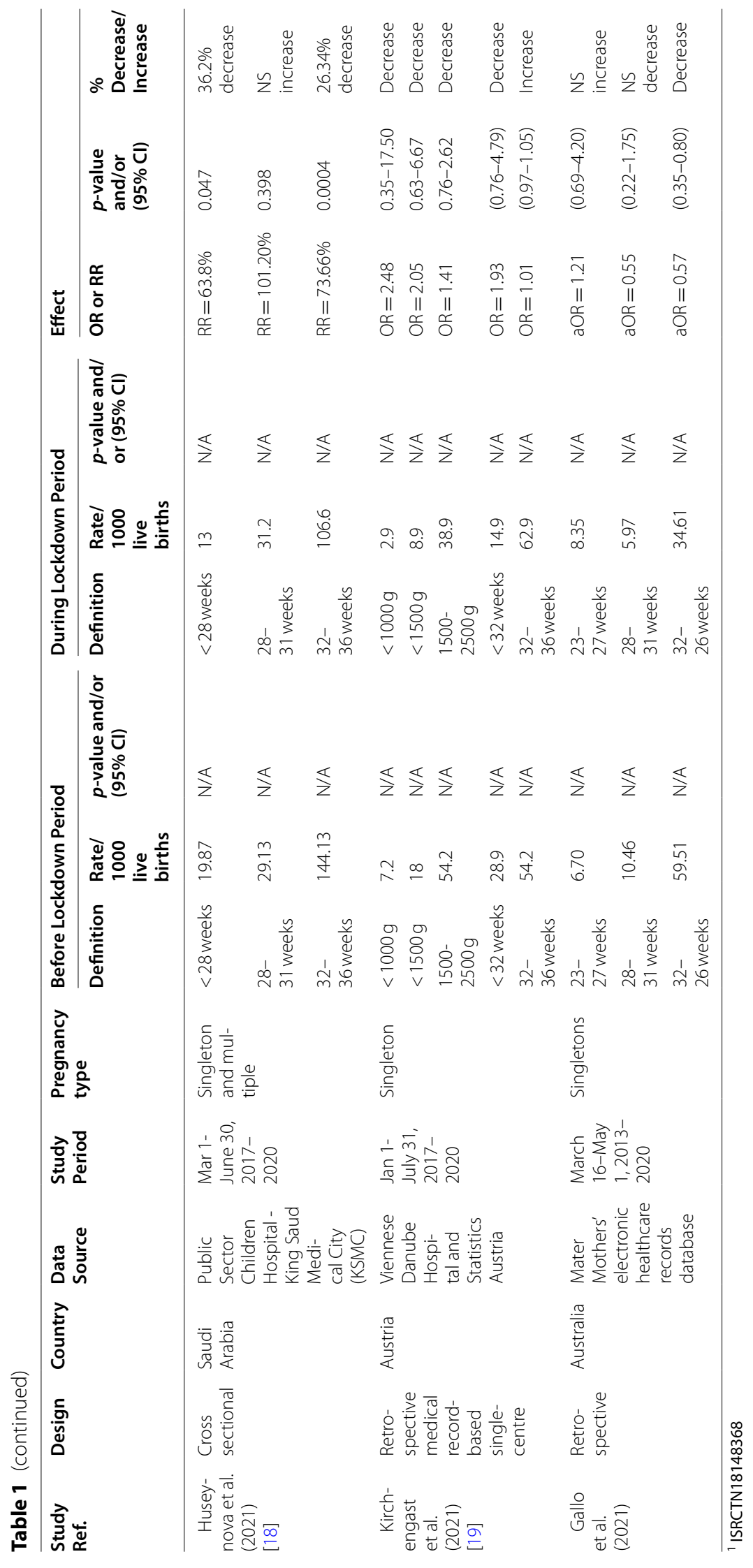




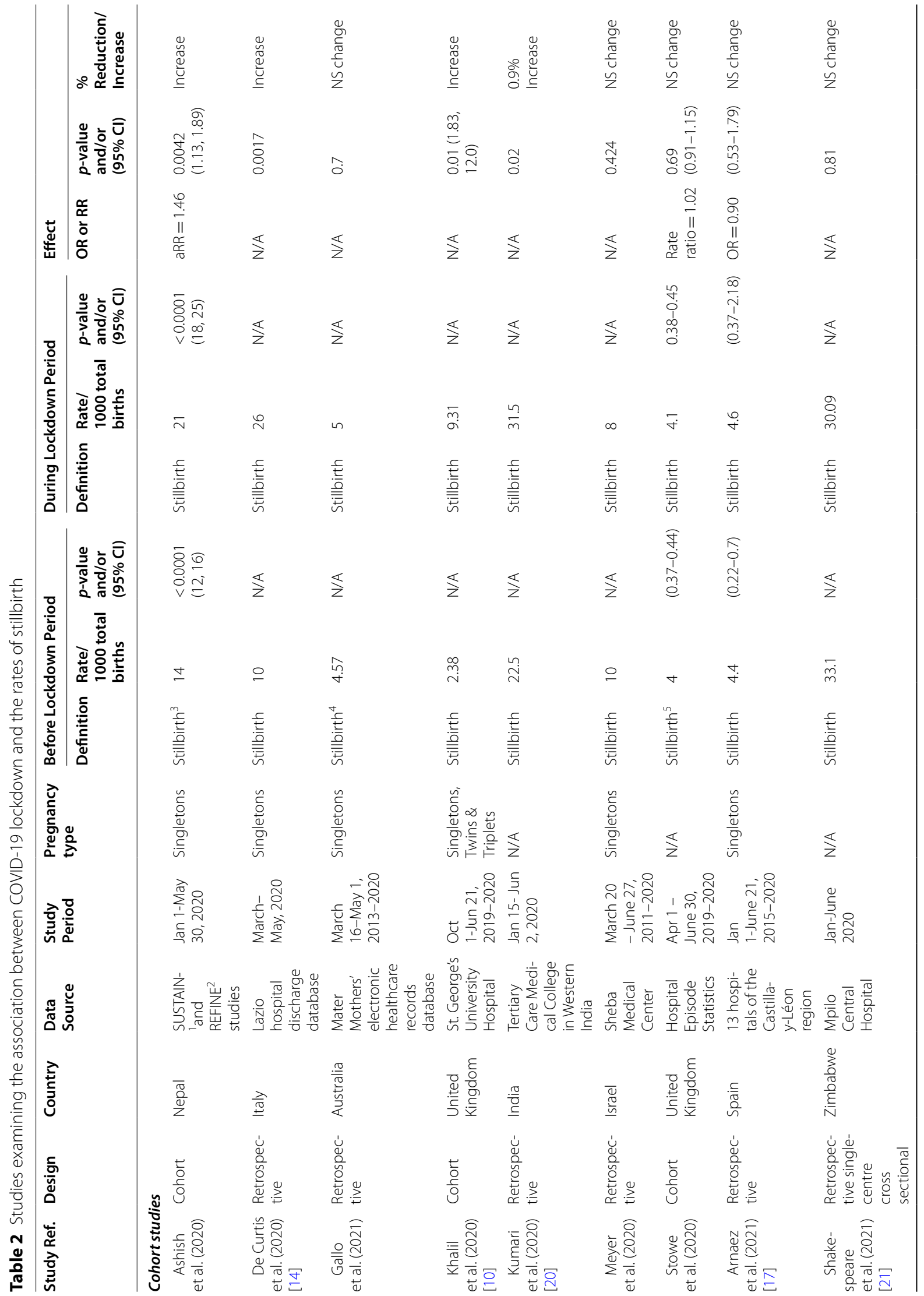




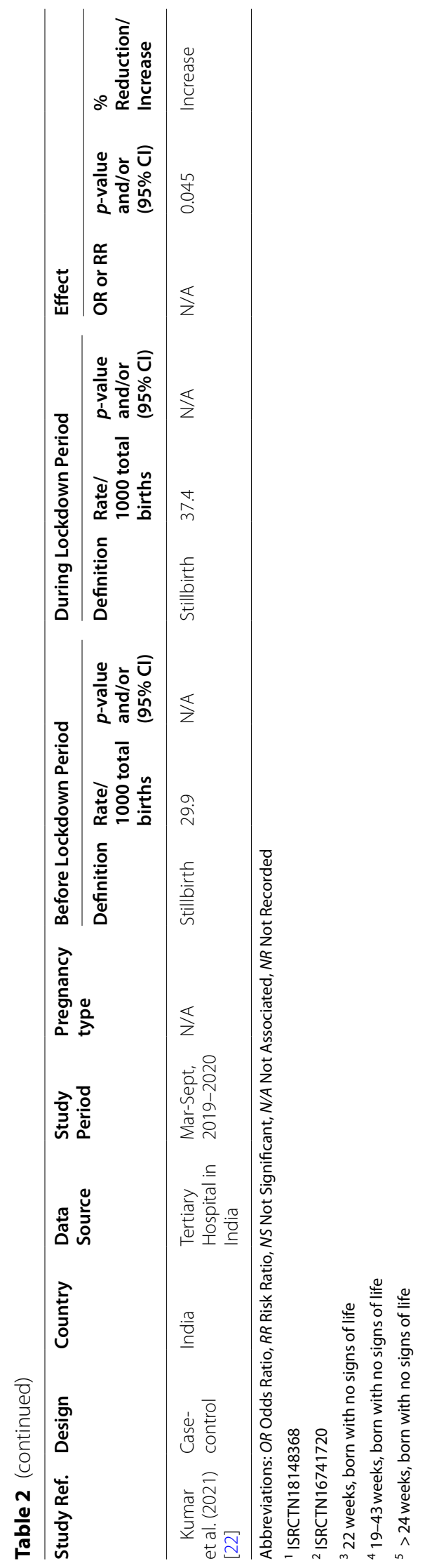


\pm 4 months) [9]. All March 9 windows saw a statistically significant decrease in preterm births $( \pm 1$ month OR 0.91 [95\% CI 0.89, 1.20]; \pm 2 months OR 0.77 [95\% CI 0.66, 0.91 ]; \pm 3 months OR 0.85 [95\% CI $0.73,0.98$ ]; \pm 4 months OR 0.84 [95\% CI 0.73, 0.97]).The 15 March 2020 windows saw no significant decreases in preterm births, and after 23 March 2020,there were no statistically significant changes observed [9].

Denmark's first wave national lockdown began 12 March 2020, with a slow reopening commencing on14 April 2020 [23]. Hedermann et al. looked at the premature birth rates of 31,180 live singleton infants born between 12 March - 14 April from 2015 to 2020. In comparison to previous years, there was an $86.8 \%$ significant reduction in infants born less than 28 weeks gestation, OR 0.09 [95\% CI 0.01, 0.40] [9]. There were non-significant changes in preterm births for the other two gestational age categories,28-31 weeks (OR 1.11 [95\% CI 0.75, 1.61] and 32-36weeks (OR 0.98 [95\% CI 0.84,1.13] [23] (Table 1).

Based on observational birth outcomes surveillance study at 8 governmental maternity wards in Botswana, Caniglia et al., with 68,448 women, examined preterm birth ( $<37$ weeks) and very preterm birth ( $<32$ weeks) in singleton newborn recorded before lockdown (January 1 , 2020 to April 2, 2020), during lockdown (April 3, 2020 to May 7, 2020), and post-lockdown (May 8, 2020 to July 20, 2020) [16].Using difference-in-differences analysis, 9\% relative reduction in preterm birth was associated with the lockdown period $(-1.52 \%$ [ $95 \% \mathrm{CI},-3.14$ to $0.10 \%])$ compared to pre-lockdown period and decreased by $0.91 \%$ ( $95 \% \mathrm{CI},-2.57$ to $0.75 \%$ ) during post-lockdown versus pre-lockdown [16]. While for severe preterm birth, a significant decrease by $-0.88 \%(95 \% \mathrm{CI},-1.46 \%$ to $-0.31 \%)$ during the post-lockdown compared to before lockdown and by $-0.26 \%$ (95\% CI, -0.80 to $0.27 \%$ ) during lockdown versus before lockdown was observed [16]. The greatest impact on the outcomes was shown to be among pregnant women with human immunodeficiency virus and those living in urban areas.

Matheson et al. conducted an interrupted time-series analysis on the monthly rate of preterm birth on singleton and multiple pregnancies in three maternity hospitals in Melbourne during lockdown [13]. The researchers analyzed 2448 births during lockdown (July to September 2020) and 2514 births during the same period in 2019. Significant lower rates of preterm birth were observed before 28 weeks of gestation with $\mathrm{OR}=0.45(95 \% \mathrm{CI}$, 0.21-0.99), before 34 weeks (OR 0.71, 95\% CI 0.51-0.98), and before 37 weeks (OR 0.81,95\% CI, 0.67-0.98) [13]. Matheson et al. found that the effect was independent of multiple pregnancies for births less than 34weeks with adjusted OR of 0.71 (95\% CI, 0.53-0.96) [13].
A retrospective cohort study in Lezio hospital, Italy, by De Curtis et al. examined very preterm birth ( $<32$ weeks) and late preterm birth rates (32-36 weeks) in singleton births during lockdown period (March to May 2020) and the same period in 2019. There was a non-significant increase $(p=0.06)$ in the rate of very preterm birth $0.55 \%(n=50)$ and $0.79 \%(n=61)$ before and during the lockdown [14]. Compared with before the lockdown period, the percentage of late preterm births detected during the lockdown period has dropped significantly from 5.93 to $4.62 \%(p<0.001)$ [14].

At Sheba Medical Center, Israel, Meyer et al. examined 31,428 singleton pregnancies during 3 periods: lockdown from March 20 to June 27, 2020, the same period during 2019 and a matched period from 2011 to 2019 [24]. Preterm birth rate at less than 34 weeks of gestation was significantly lower in the lockdown period than in both the parallel period in 2019 and matched period from 2011 to 2019 with $\mathrm{OR}=0.45$ [95\% CI, 0.30,0.68] and OR $=0.60$ [95\% CI, 0.41,0.85], respectively [24]. Furthermore, preterm birth at less than 32 weeks of gestation was significantly reduced in the pandemic period compared with the 2019 and $2011-2019$ periods; OR $=0.47$ [95\% CI, $0.27,0.79]$ and $\mathrm{OR}=0.58$ [95\% CI, $0.37,0.92]$, respectively [24].

Based on cross-sectional study at the Neonatal Intensive Care Unit, King Saud Medical City, in Saudi Arabia, Huseynova R. et al., with 7226 live births, examined extremely preterm $(24-27$ weeks +6 days $)$, very preterm (28-31 weeks +6 days), and moderate to late preterm (32-36 weeks +6 days) recorded between March 1 till June 30, 2017-2020 [18]. Among 1320 preterm infants, the authors observed a $23 \%$ decline in the overall preterm birth during lockdown period (March1-June 30, 2020) with a signicant $36 \%(p=0.047)$ and $26.34 \%(p=0.0004)$ prevented fraction of extremely preterm and moderate to late premature births, respectively [18].

Kirchengast S. examined 669 singleton live births in Austria during the lockdown period between March and July 2020 compared to prelockdown period (JanuaryFebruary 2020) and during the last 15 years (2005-2019) [19]. The results showed that the rate of very preterm birth ( $<32$ weeks) during the lockdown months was markedly lower than prelockdown. However, no significant decrease in late preterm birth rate was observed (OR 1.01, CI 0.97-1.05) [19].

In contrast, some evidence suggests that lockdown had no significant impact on preterm birth rate $[10,15,17]$. A single center cohort study ( $n=3462$ births) by Khalil et al. was conducted at St. George's University Hospital in the United Kingdom. The investigators observed nonsignificant increases in preterm births for gestations less 
than 34 weeks [ $95 \%$ CI $-2.43,1.07]$ and 37 weeks [95\% CI $-0.05,2.30]$ ) (Table 1) [10].

In a large tertiary care center in Israel, Justman et al. conducted a cross-sectional study to examine preterm birth [15]. The researchers compared 310 births during lockdown period (March to April 2020) with 742 births before the pandemic (March to April 2019). A nonsignificant change was detected in preterm birth at less than 32 weeks $(p=0.63)$ and preterm births at less than 37 weeks $(p=0.96)$ between lockdown period and the same period in 2019 [15].

Arnaez et al. examined 70,024 births born from January 1,2015 , to June 21,2020 , in a population prevalence proportion study across 13 hospitals [17]. Preterm birth rates did not significantly decrease in during the lockdown period or de-escalation period compared to the prelockdown period (OR 0.93, 95\% CI 0.75-1.15 and OR $0.99,95 \%$ CI $0.85-1.15$, respectively [17].

In Nepal, a national lockdown due to COVID-19 began on 21 March 2020 [25]. A prospective cohort study, with 20,354 mothers by Ashish et al., examined singleton preterm birth rates 2.5 weeks before lockdown ( 1 January 2020-20 March 2020) compared to 9.5 weeks of lockdown (21 March 2020-30 May 2020). Preterm birth rates (<37 weeks) increased by $16.5 \%$ (aRR 1.3 and $95 \%$ CI [1.2, 1.4]) during the lockdown period [25].

In the meta-analysis, there were 3410 PTB ( $<37$ weeks) among 33,679 singleton and multiple births in the lockdown period compared with 11,327 PTB among 132,450 neonates in the pre-lockdown period. Significant heterogeneity was detected $\left(\mathrm{I}^{2}=82 \%\right.$ and $\left.p<0.00001\right)$ (Fig. 1 ). Meta-analyses showed that lockdown was not associated with a significant increased/decreased risk of PTB when compared to before lockdown period $(\mathrm{RR}=0.93[95 \% \mathrm{CI}$ $0.84,1.03])$.

\section{Low birth weight}

Four national cohort studies compared the rates of low birth weight before versus during the first wave of COVID-19 pandemic (Table 1) [11, 17, 19, 25]. The study by Ashish et al. in Nepal on singleton births $(n=20,354)$ reported a non-significant $0.05 \%$ decrease $(p=0.37)$ in low birth weight $(<2500 \mathrm{~g})$ rates from before the lockdown (1 January 2020-20 March 2020) to during the lockdown (21 March 2020-30 May 2020) [25]. Philip RK et al. study was entirely dedicated to regional low birth weight trends amongst preterm birth $(n=93,018)$ over two decades, including the period of COVID-19 first wave [11]. Preterm birth starting from 22 weeks of gestation involving low birth weight were divided into two categories: very low birth weight (VLBW) $(<1500 \mathrm{~g})$ and extremely low birth weight (ELBW) $(<1000 \mathrm{~g})$. A $73.5 \%$ reduction in VLBW was reported, with a rate ratio of 3.77 [95\% CI 1.21, 11.75]. No ELBW live births were recorded during the January-April 2020 period [11].

Kirchengast S. examined 669 singleton live births at Viennese Danube Hospital, Austria during the January-February 2020 and 2005-2019. The results showed that the rate of ELBW $(<1000 \mathrm{~g})$, VLBW $(<1500 \mathrm{~g})$, LBW (1500-2500 g) during the lockdown months (March-July 2020) was lower than prelockdown. The pre-lockdown rate of LBW newborns was significantly higher than the lockdown period (OR 1.66 [95\% CI 0.98, 2.81]) [19].

A population prevalence proportion study by Arnaez et al. investigated the rates of LBW singletons in Spain. The authors observed a non significant change in VLBW singletons $(<1500 \mathrm{~g})$. Although the rates of ELBW $(<1000 \mathrm{~g})$ singletons increased from 3.4 to 4.6 per 1000 during the lockdown period (March-May 2020), this finding was not significant (OR 1.19 [95\% CI 0.44,2.23]) [17].

\begin{tabular}{|c|c|c|c|c|c|c|c|c|c|}
\hline \multirow[b]{2}{*}{ Study or Subgroup } & \multicolumn{2}{|c|}{ PTB During Lockdown } & \multicolumn{2}{|c|}{ PTB Pre-lockdown } & \multirow[b]{2}{*}{ Weight } & \multirow{2}{*}{$\begin{array}{l}\text { Risk Ratio } \\
\text { M-H, Random, } 95 \% \mathrm{Cl}\end{array}$} & \multirow{2}{*}{\multicolumn{2}{|c|}{$\begin{array}{c}\text { Risk Ratio } \\
\mathrm{M}-\mathrm{H}, \text { Random, } 95 \% \mathrm{Cl}\end{array}$}} & \\
\hline & Events & Total & Events & Total & & & & & \\
\hline Arnaez et al. 2021 & 195 & 3005 & 4333 & 65256 & $10.6 \%$ & $0.98[0.85,1.12]$ & " & - & \\
\hline Ashish et al. 2020 & 1342 & 7165 & 2125 & 13189 & $12.5 \%$ & $1.16[1.09,1.24]$ & & $\rightarrow$ & \\
\hline Caniglia et al. 2021 & 518 & 3448 & 1316 & 8075 & $11.9 \%$ & $0.92[0.84,1.01]$ & & & \\
\hline De Curtis et al. 2020 & 419 & 7755 & 587 & 9053 & $11.1 \%$ & $0.83[0.74,0.94]$ & & & \\
\hline Gallo et al 2020 & 15 & 20 & 147 & 204 & $7.0 \%$ & $1.04[0.80,1.36]$ & & & \\
\hline Hederman et al. 2020 & 249 & 5162 & 1317 & 26018 & $10.8 \%$ & $0.95[0.84,1.09]$ & & - & \\
\hline Huseynova et al. & 266 & 1763 & 1054 & 5463 & $11.1 \%$ & $0.78[0.69,0.88]$ & & & \\
\hline Justman et al. 2020 & 39 & 610 & 48 & 742 & $4.3 \%$ & $0.99[0.66,1.49]$ & & & \\
\hline Khalil et al. 2020 & 113 & 1655 & 127 & 1692 & $7.6 \%$ & $0.91[0.71,1.16]$ & & - & \\
\hline Kirchengast et al. 2021 & 52 & 669 & 23 & 277 & $3.5 \%$ & $0.94[0.58,1.50]$ & & & \\
\hline Matheson et al. 2021 & 202 & 2427 & 250 & 2481 & $9.5 \%$ & $0.83[0.69,0.99]$ & & & \\
\hline Total $(95 \% \mathrm{Cl})$ & & 33679 & & 132450 & $100.0 \%$ & $0.93[0.84,1.03]$ & & & \\
\hline Total events & 3410 & & 11327 & & & & & & \\
\hline \multicolumn{5}{|c|}{$\begin{array}{l}\text { Heterogeneity: } \text { Tau }^{2}=0.02 ; \mathrm{Chi}^{2}=54.96, \mathrm{df}=10(P<0.00001) ; \mathrm{I}^{2}=82 \% \\
\text { Test for overall effect: } Z=1.35(P=0.18)\end{array}$} & & 0.5 & $\begin{array}{c}0.7 \\
\text { During Lockdown }^{1}\end{array}$ & $\begin{array}{r}1.5 \\
\text { Pre-lockdown }\end{array}$ & 2 \\
\hline
\end{tabular}


Meta-analyses showed no significant risk of LBW and VLBW between groups with $\mathrm{RR}=0.57$ [95\% CI 0.24, 1.38 and $R R=0.58$ [95\% CI $0.17,1.97$ ], respectively (Fig. 2a, b).

\section{Stillbirth}

Studies have reported that stillbirths across different countries increased [10,14, 20,22, 25] or remained unchanged [17, 21, 24, 26, 27] during COVID-19 first wave lockdown. Stillbirth is defined as either fetal death with a gestational age of at least 19 weeks, at least 22 weeks [25] or at least 24weeks [9, 27] (Table 2). The prospective cohort study in Nepal by Ashish et al. described singleton stillbirth rates $(n=20,354)$ 12.5 weeks before lockdown (1 January 2020to 20 March 2020) and 9.5 weeks during lockdown (21 March 2020-30 May 2020) [25]. Babies born after at least 22 weeks with no signs of life were defined as stillbirths. The adjusted risk ratio of institutional stillbirth rates during the COVID-19 first wave lockdown compared to the period before lockdown was 1.46 [95\% CI 1.13, 1.89]) [25].

The previously described cohort study in the United Kingdom by Khalil et al. compared stillbirth rates between the pre-pandemic period (1 October 2019-1 January 2020, $n=1681$ ) and the first wave pandemic period (1 February 2020-14 June 2020, $n=1718$ ) [10]. Fetal deaths with a gestational age of at least 24 weeks were considered stillbirths. Stillbirth rate during the COVID-19 first wave pandemic period was higher than during the pre-pandemic period, with a difference of 6.93/1000 births [95\% CI 1.83, 12.0] [10].
Of the 6209 pregnant women during lockdown, a retrospective analysis by Kumari et al. across four hospitals in India showed that lockdown has resulted in a significant $0.9 \%$ increase in stillbirth $(p=0.02)$ compared with the pre-lockdown period [20].

Similarly, a retrospective study in Italy by De Curtis et al. compared the singleton stillbirth rates during the three-month lockdown (March to May) in 2020 to the stillbirth rates during the same months in 2019. A threefold increase in stillbirths was observed when the stillbirth rate went from 10 to 26 per 1000 total births between 2019 and 2020 ( $p=0.0017)$ [14].

A case-control study by Kumar et al. compared the rates of stillbirth from March-September 2019 to the same months in 2020 in a single tertiary care center in India. A modest increase, from 29.9 to 37.4 per 1000 births was seen between 2019 and $2020(p=-0.045)$ [17].

However, other studies found no significant differences in stillbirth rates before and during the pandemic $[17,21$, 24, 26, 27]. In England, Stowe et al. found that the incidence rate ratio of stillbirths during lockdown (April 1, 2020, and June 30, 2020) was 1.02 [95\% CI,0.91-1.15]; $p=0.69$ compared with stillbirth during the same period in 2019. Furthermore, within the 4 English regions, the rate of stillbirth was not significantly different between the pre-pandemic and lockdown periods [27]. Gallo et al. examined stillbirth rates of 10,044 singleton pregnancies at a tertiary perinatal hospital in Queensland from March 16 to May 1, 2020, compared with same period from 2013 to 2019. Stillbirth prevalence did not differ between

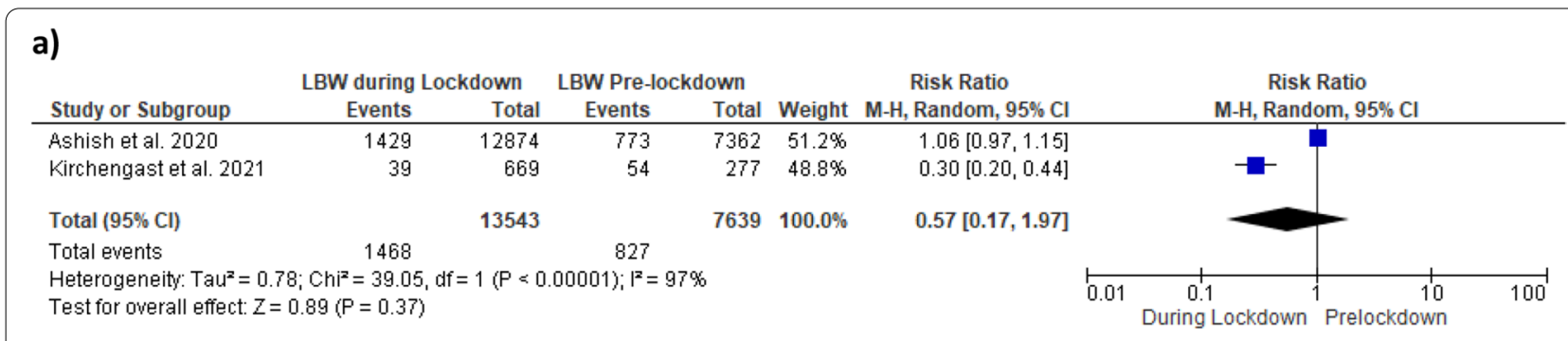

b)

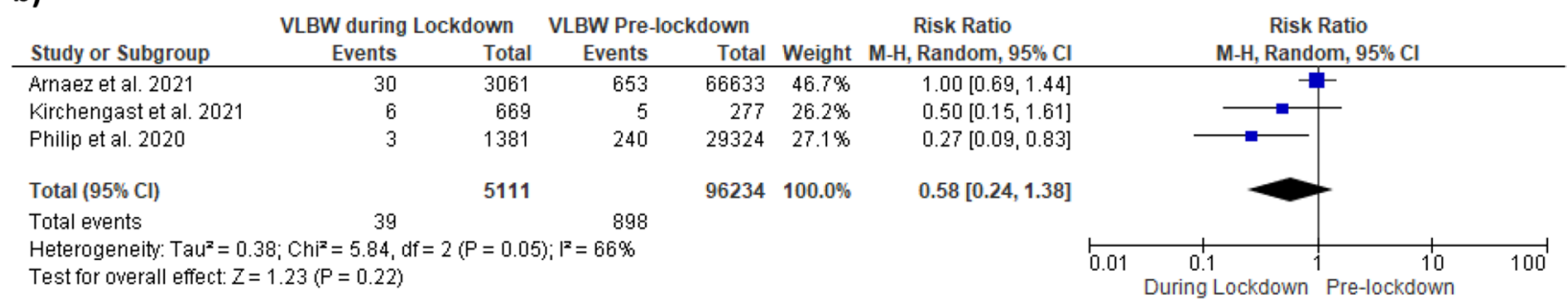

Fig. 2 Forest plots of a low birthweight and $\mathbf{b}$ very low birthweight before and during COVID-19 lockdown periods 
the examined years $(p=0.70)$ [26]. Meyer et al. collected the singleton stillbirth rates at the Sheba Medical Center, Israel, during the COVID-19 period from March 20 to June 27, $2020(n=25,940)$, during a 2019 parallel prepandemic period $(n=2742)$, and during parallel annual periods ranging from 2011 to $2019(n=28,686)$. It was observed that there was no change between the pandemic and pre-pandemic periods stillbirth rates $(p=0.424)$ [24]. Shakespeare et al. examined stillbirth rates at Mpilo Central Hospital, Zimbabwe from January-March 2020 and April-June 2020 using a cross-sectional design. The rate of stillbirth at Mpilo Central Hospital decreased from 33.1 to 30.09 per 1000 births, however this decline was not statistically significant $(p=0.81)$ [21]. Lastly, a study by Arnaez et al. examined the rate of stillbirth singletons in 13 hospitals located in the Castilla-y-Léon region of Spain. In comparison to the lockdown period, changes in stillbirth rates between the pre-pandemic period in 2020 (OR 0.90 [95\% CI 0.37,2.18]) or previous years (OR 1.22 [95\% CI 0.45,3.23]) were not significant [17].

The meta-analysis included 901 stillbirth among 150,219 neonates in the lockdown period compared with 1279 stillbirth among 234,187 neonates in the pre-lockdown period. Lockdown was associated with a higher risk of still birth than that of pre-lockdown period $(\mathrm{RR}=1.33$ [95\% CI 1.04, 1.69]) (Fig. 3).

\section{Discussion}

The current review described conflicting evidence from large studies reporting both increases and decreases in perinatal outcomes during the COVID-19 first wave lockdowns. The meta-analysis showed a significant association between lockdown measures and increased risk of stillbirths, and no association with preterm births, LBW or VLBW. Preterm birth, low birth weight and stillbirth have puzzled researchers for years to predict and prevent their incidence. However, the socio-environmental, cultural, and economic conditions of the lockdown due to COVID-19 have served to facilitate the understanding of the occurrence of perinatal outcomes during exceptional periods. Studies from Netherlands and Denmark have reported significant reduction in preterm birth rate [9, $11,23]$ and non-significant decrease in low birth weight $[11,25]$. Additionally, a large study using data from Ireland has adopted very low birth weight and extremely low birth weight infants to evaluate the rate of preterm birth (not the traditional definition of LBW) [11]. Different mechanisms of action were suggested to explain the reported associations. Authors hypothesized that these outcomes are associated with better hygiene measures $[9$, $23]$, enhanced public vigilance $[16,28]$, reduced air pollution $[9,29,30]$, increased companionship and social support [26, 31, 32], reduced anxiety [33], less work-related stress [9, 23, 34], and an uptake in maternal wellbeing $[9,29]$. However, Been et al. emphasized that in terms of health care and the economy, pandemics and blockades have exacerbated the already existing inequalities among the population [9]. In fact, this is noticeable as underdeveloped countries like Nepal, have rather reported an increase in preterm and still birth rates during the COVID-19 first wave lockdown. Ashish et al. stated that theCOVID-19 first wave has caused women to avoid health facilities and has underlined the overall low-quality of maternal and neonatal care [25]. This highlights that the implementation of lockdowns and the degree of outbreaks had the potential to affect individuals' health and access to health care. Depending on the disparities faced by these individuals in each study, underreporting of adverse birth outcomes may have occurred. Moreover, mothers in Nepal and Zimbabwe experienced increased stress, due to social restrictions and financial insecurity [25, 32, 35]. Two studies, Been et al. and Gallo et al., described the socioeconomic status of the study population. Gallo et al. adjusted for the socioeconomic

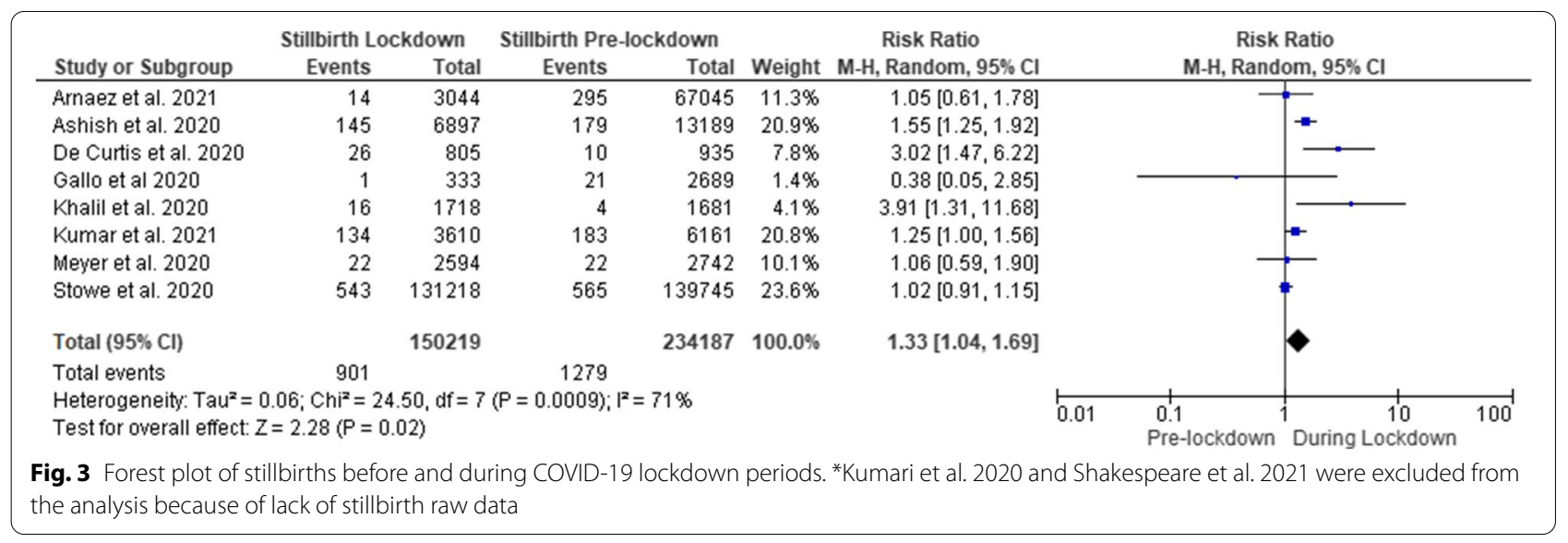


status by residence and found no significant difference in extremely preterm or very preterm births between pandemic and prepandemic periods. Additionally, Been et al. tested for effect modification of perinatal outcomes by neighborhood socioeconomic status and it was not statistically significant.

Changes in the adverse outcomes among pregnant women at different pandemic periods suggest that the lockdown could have affected pregnant women to a larger extent. Although two national Cohort studies in Denmark and Botswana reported lower rates of preterm births during the pandemic lockdown, these studies assessed only 1 month of the lockdown period [16, 23]. Canigilia et al. found a greater reduction during the postlockdown period than during lockdown period in Botswana. This could be attributed to the delayed influence of lockdown restrictions on pregnancy outcomes based on the pregnancy trimester [16]. The analysis captured a diverse set of trial designs to clarify the difference in perinatal outcomes before and during lockdown periods. Lockdown was associated with an increase in stillbirth rate and non-significant change in both PTB, LBW and VLBW when compared with pre-lockdown period.

The current findings have important clinical significance as they provide evidence that first wave lockdown affected perinatal outcomes in different forms. Although Been et al. observed a reduction in preterm births, the authors could not determine if this decline occurred at the expense of high stillbirths' rates, mainly due to insufficient up-to-date information on stillbirths [9].

Limitations of this rapid review should be acknowledged; the search was limited to articles published in English, the primary research was done within a short period of time, and risk of bias could not be excluded in the included studies. Despite these limitations, this review provides clues about the severity of the indirect influence of COVID-19 first wave lockdown implementation, which appears to be more serious than the direct impact, in the prevention of neonatal outcomes during pandemic. Also, sociodemographic and economic data of low/middle income countries and variation in strict lockdown strategies across countries are worthy of further investigation to develop effective strategies for the second wave and other future pandemics. COVID-19 measures have been implemented with significant variation across countries which resulted in differences in risk factors associated with stillbirth, preterm birth and low birthweight. An international collaborative effort is the essential next step to assess the association between the COVID-19 lockdown measures and still birth rates, which will be crucial for the development of preventive strategies especially in low- to middle-income countries. Further studies are needed to robustly assess whether perinatal complications are affected by COVID-19 lockdown measures compared to pre-pandemic periods. Furthermore, additional research is needed to study major determinants, such as ethnicity and socioeconomic status, and COVID-19 related maternal and neonatal outcomes. With the waves of lockdown currently implemented in several countries, researchers would be able to investigate perinatal outcomes across different demographic strata at different time-periods.

\section{Conclusions}

This review highlights the COVID-19 first wave lockdowns conflicting impact on perinatal outcomes, as evidenced by the recent studies. First wave lockdown was associated with higher risk of reported stillbirth. The observed inconsistent evidence highlights the importance of implementing tailored and rapid-response preventive policies as new evidence emerges. Decision makers should regularly monitor perinatal care and neonatal outcomes throughout the waves of the pandemic, while developing plans for prompt interventions. The results also raise concerns of the social inequalities and healthcare conditions in less developed countries. Nonetheless, the indirect impact of lockdown measures in different countries on perinatal outcomes is worth further study.

\section{Strengths and limitations of this review}

We provided a detailed rapid review and meta-analysis of perinatal outcomes during the COVID-19 first wave lockdowns from developed and developing countries. This review included information on three major perinatal outcomes, stillbirth, preterm births, and low birth weight. As for the limitations of this review, this is a rapid review - not as thorough in nature as a systematic review.

\section{Abbreviations \\ COVID-19: Corona Virus Disease 2019; ELBW: Extremely Low Birth Weight; LBW: Low Birth Weight; OR: Odds Ratio; PTB: Preterm Births; RR: Risk Ratio; VLBW: Very Low Birth Weight.}

\section{Supplementary Information}

The online version contains supplementary material available at https://doi. org/10.1186/s12884-021-04156-y.

Additional file 1. Screening tool for located studies.

Acknowledgements

Not applicable.

Authors' contributions

C.V., F.M., L.A., and S.E. contributed to the concept and design of the study. C.V., F.M., L.A., B.A., and S.E. contributed to drafting and revising of the full 
manuscript and have approved the manuscript as submitted. C.V., F.M., L.A. B.A., and S.E. have met the criteria of authorship, and take public responsibility for the manuscript contents. C.V. is the first author and S.E. is the corresponding author of the review.

\section{Funding}

This work was supported by Research Manitoba (\#4443).

\section{Availability of data and materials}

All materials and data used for this review have been provided in the reference list.

\section{Declarations}

\section{Ethics approval and consent to participate}

Not applicable.

\section{Consent for publication}

Not applicable.

\section{Competing interests}

The authors declare that they have no competing interests.

\section{Author details}

${ }^{1}$ College of Pharmacy, Rady Faculty of Health Sciences, University of Manitoba, Winnipeg, Canada. ${ }^{2}$ Faculty of Pharmacy, Universite de Montreal, Montréal, Canada. ${ }^{3}$ The Children's Hospital Research Institute of Manitoba, Winnipeg, Canada.

Received: 7 April 2021 Accepted: 22 September 2021

Published online: 06 October 2021

\section{References}

1. Statement on the second meeting of the International Health Regulations (2005) Emergency Committee regarding the outbreak of novel coronavirus (2019-nCov).

2. Ferguson S, Davis D, Browne J. Does antenatal education affect labour and birth? A structured review of the literature. Women Birth. 2013;26(1):e5. https://doi.org/10.1016/j.wombi.2012.09.003.

3. Chawanpaiboon S, Vogel JP, Moller AB, Lumbiganon P, Petzold M, Hogan $D$, et al. Global, regional, and national estimates of levels of preterm birth in 2014: a systematic review and modelling analysis. Lancet Glob Heal. 2019;7(1):e37-46. https://doi.org/10.1016/S2214-109X(18)30451-0.

4. Blencowe H, Krasevec J, de Onis M, Black RE, An X, Stevens GA, et al. National, regional, and worldwide estimates of low birthweight in 2015, with trends from 2000: a systematic analysis. Lancet Glob Heal. 2019;7(7):e849-60. https://doi.org/10.1016/S2214-109X(18)30565-5.

5. Blencowe H, Cousens S, Jassir FB, Say L, Chou D, Mathers C, et al. National, regional, and worldwide estimates of stillbirth rates in 2015, with trends from 2000: A systematic analysis. Lancet Glob Heal. 2016;4(2):e98-108. https://doi.org/10.1016/S2214-109X(15)00275-2.

6. Canadian hospitals saw a sudden drop in premature births during the pandemic. Now researchers are trying to find out why - The Globe and Mail [Internet]. [cited 2021 Apr 2]. https://www.theglobeandmail.com/ canada/alberta/article-canadian-hospitals-saw-a-sudden-drop-in-prema ture-births-during-the/.

7. Fewer babies are being born premature during COVID-19|CTV News [Internet]. [cited 2021 Apr 2]. https://www.ctvnews.ca/health/fewerbabies-are-being-born-premature-during-covid-19-1.5056815.

8. Calgary doctor says "dramatic" $40 \%$ drop in preterm births during lockdown could be global trend | CBC News [Internet]. [cited 2021 Apr 2]. https://www.cbc.ca/news/canada/calgary/fewer-premature-pretermbabies-born-during-pandemic-calgary-around-the-world-

9. Been JV, Burgos Ochoa L, Bertens LCM, Schoenmakers S, Steegers EAP, Reiss IKM. Impact of COVID-19 mitigation measures on the incidence of preterm birth: a national quasi-experimental study. Lancet Public Heal. 2020;5(11):e604-11. https://doi.org/10.1016/S2468-2667(20) 30223-1.
10. Khalil A, von Dadelszen P, Draycott T, Ugwumadu A, O'Brien P, Magee L. Change in the Incidence of Stillbirth and Preterm Delivery During the COVID-19 Pandemic. JAMA. 2020;324(7):705-6. https://doi.org/10. 1001/jama.2020.12746.

11. Philip RK, Purtill $H$, Reidy E, et al. Reduction in preterm births during the COVID-19 lockdown in Ireland: a natural experiment allowing analysis of data from the prior two decades. medRxiv. 2020; 2020.06.03.20121442.

12. Matheson A, McGannon CJ, Malhotra A, Palmer KR, Stewart AE, Wallace EM, et al. Prematurity rates during the coronavirus disease 2019 (COVID-19) pandemic lockdown in Melbourne, Australia. Obstet Gynecol. 2021;137(3):2019-21. https://doi.org/10.1097/AOG.0000000000004236.

13. Matheson A, McGannon CJ, Malhotra A, Palmer KR, Stewart AE, Wallace EM, et al. Prematurity rates during the coronavirus disease 2019 (COVID-19) pandemic lockdown in Melbourne, Australia. Obstet Gynecol. 2021;137(3):405-7.

14. De Curtis M, Villani L, Polo A. Increase of stillbirth and decrease of late preterm infants during the COVID-19 pandemic lockdown. BMJ Arch Dis Child Fetal Neonatal Ed. 2020;0:F1. https://doi.org/10.1001/jama.2020. 12746.

15. Justman N, Shahak GGO, et al. Lockdown with a Price: the impact of the COVID-19 pandemic on prenatal care and perinatal outcomes in a tertiary care center. Isr Med Assoc J. 2020;22(9):533-7.

16. Caniglia EC, Magosi LE, Zash R, Diseko M, Mayondi G, Mabuta J, et al. Modest reduction in adverse birth outcomes following the COVID-19 lockdown. Am J Obstet Gynecol. 2021;224(6):615.e1-615.e12. https://doi. org/10.1016/j.ajog.2020.12.1198.

17. Arnaez J, Ochoa-Sangrador C, Caserío S, Gutiérrez EP, Jiménez M. del P, Castañón L, et al. lack of changes in preterm delivery and stillbirths during COVID-19 lockdown in a European region. Eur J Pediatr. 2021;180(6):1997-2002.

18. Huseynova R, Bin Mahmoud L, Abdelrahim A, Al Hemaid M, Almuhaini $M S$, Jaganathan PP, et al. Prevalence of preterm birth rate during COVID19 lockdown in a tertiary care hospital, Riyadh. Cureus. 2021;13(3):1-8.

19. Kirchengast $S$, Hartmann B. Pregnancy outcome during the first covid 19 lockdown in Vienna, Austria. Int J Environ Res Public Health. 2021;18(7):1-14.

20. Kumari V, Mehta KCR. COVID-19 outbreak and decreased hospitalisation of pregnant women in labour. Lancet Glob Heal. 2020;8(9):e1116-7. https://doi.org/10.1016/S2214-109X(20)30319-3.

21. Shakespeare C, Dube H, Moyo S, Ngwenya S. Resilience and vulnerability of maternity services in Zimbabwe: a comparative analysis of the effect of Covid-19 and lockdown control measures on maternal and perinatal outcomes, a single-Centre cross-sectional study at Mpilo central hospital. BMC Pregnancy Childbirth. 2021;21(1):1-8. https://doi.org/10.1186/ s12884-021-03884-5.

22. Kumar M, Puri M, Yadav R, Biswas R, Singh M, Chaudhary V, et al. Stillbirths and the COVID-19 pandemic: looking beyond SARS-CoV-2 infection. Int J Gynecol Obstet. 2021;153(1):76-82.

23. Hedermann G, Hedley PL, Bækvad-Hansen M, Hjalgrim H, Rostgaard K, Poorisrisak P, et al. Danish premature birth rates during the COVID-19 lockdown. Arch Dis Child Fetal Neonatal Ed. 2021;106(1):F93-5.

24. Meyer R, Bart Y, Tsur A, Yinon Y, Friedrich L, Maixner N, et al. A marked decrease in preterm deliveries during the coronavirus disease 2019 pandemic. Am J Obstet Gynecol. 2021;224(2):234-7. https://doi.org/10. 1016/j.ajog.2020.10.017.

25. KC A, Gurung R, Kinney M V., Sunny AK, Moinuddin M, Basnet O, et al. Effect of the COVID-19 pandemic response on intrapartum care, stillbirth, and neonatal mortality outcomes in Nepal: a prospective observational study. Lancet Glob Heal. 2020;8(10):e1273-81.

26. Gallo LA, Gallo TF, Borg DJ, Moritz KM, Clifton VL, Kumar S. Preterm birth rates in a large tertiary Australian maternity centre during COVID-19 mitigation measures. medRxiv. 2020;(January) 2020.11.24.20237529. https:// doi.org/10.1101/2020.11.24.20237529.

27. Stowe J, Smith H, Thurland K, et al. Stillbirths During the COVID-19 Pandemic in England, April-June 2020. JAMA. 2021;325(1). https://doi.org/10. 1001/jama.2020.21369.

28. Delnord M, Blondel B, Zeitlin J. What contributes to disparities in the preterm birth rate in European countries? Curr Opin Obstet Gynecol. 2015;27(2):133-42. https://doi.org/10.1097/GCO.0000000000000156. 
29. Huang L, Fan L, Ding P, He YH, Xie C, Niu Z, et al. Maternal exercise during pregnancy reduces the risk of preterm birth through the mediating role of placenta. J Matern Neonatal Med. 2019;32(1):109-16. https://doi.org/ 10.1080/14767058.2017.1372415.

30. Sun Z, Yang L, Bai X, Du W, Shen G, Fei J, et al. Maternal ambient air pollution exposure with spatial-temporal variations and preterm birth risk assessment during 2013-2017 in Zhejiang Province, China. Environ Int. 2019;133(September):105242. https://doi.org/10.1016/j.envint.2019. 105242.

31. Wheeler S, Maxson P, Truong TSG. Psychosocial stress and preterm birth: the impact of parity and race. Matern Child Heal J. 2018;22(10):1430-5. https://doi.org/10.1007/s10995-018-2523-0.

32. Stacey T, Prady S, Haith-Cooper M, Downe S, Simpson N, Pickett K Ethno-specific risk factors for adverse pregnancy outcomes: findings from the born in Bradford cohort study. Matern Child Health J. 2016;20(7):1394-404.
33. Kramer MS, Lydon J, Séguin L, Goulet L, Kahn SR, McNamara H, et al. Stress pathways to spontaneous preterm birth: the role of stressors, psychological distress, and stress hormones. Am J Epidemiol. 2009;169(11):1319-26. https://doi.org/10.1093/aje/kwp061.

34. Cai $C$, et al. The impact of occupational shift work and working hours during pregnancy on health outcomes: a systematic review and metaanalysis. Am J Obstet Gynecol. 2019;221(6):563-76. https://doi.org/10. 1016/j.ajog.2019.06.051.

35. Madden D. The relationship between low birth weight and socioeconomic status in Ireland. J Biosoc Sci. 2014;46(2):248-65. https://doi.org/ 10.1017/S0021932013000187.

\section{Publisher's Note}

Springer Nature remains neutral with regard to jurisdictional claims in published maps and institutional affiliations.
Ready to submit your research? Choose BMC and benefit from:

- fast, convenient online submission

- thorough peer review by experienced researchers in your field

- rapid publication on acceptance

- support for research data, including large and complex data types

- gold Open Access which fosters wider collaboration and increased citations

- maximum visibility for your research: over 100M website views per year

At BMC, research is always in progress.

Learn more biomedcentral.com/submissions 